\title{
On the Cytological Features exhibited by certain Varietal and Hybrid Ferns.
}

BY

J. BRETLAND FARMER, F.R.S.,

AND

L. DIGBY.

With Plates XVI-XVIII.

THE last few years have witnessed the publication of the results of a number of investigations on the cytology of hybrid plants, and far-reaching inferences as to the significance of the chromosomes have been drawn from them. But the views of different investigators are somewhat widely divergent. Some have concluded that the frequent sterility of the hybrid is the result of an incompatibility between the parental chromosomes which enter into the nuclear constitution of the hybrid, whilst others, notably Tischler, ${ }^{1}$ seem to attribute the failure of the reproductive processes to a disturbance of the normal relations of nucleus and cytoplasm.

This latter conclusion is in harmony with the views advanced by R. Hertwig, according to whom the individual chromosomes are of comparatively little significance, whilst the matter of supreme importance consists in the maintenance of certain definite relations between the nucleus and the cytoplasm which he embodied in his well-known formula $\mathrm{K} / \mathrm{P}$.

The recent work of Popoff, ${ }^{2}$ as well as the very valuable results obtained in earlier years by Klebs, ${ }^{3}$ also points to the need of keeping in mind the mutual relations of nucleus and cytoplasm which have been too much ignored by some writers. We have seen no reason for departing from the position already taken up by one of us in $1905^{4}$ to the effect that whilst the cytoplasm chiefly supplies the raw material for development, and

1 Tischler, G., Zellstudien an sterilen Bastardpflanzen. Arch. f. Zellforschung, Bd. i.

2 Popoff, M., Experimentelle Zellstudien. Arch. f. Zellforsch., Bd.i.

3 Klebs, G., Die Bedingungen der Fortpflanzung, I896, and other papers by the same author.

${ }^{4}$ Farmer, J. B., and Moore, J. E. S., Quart. Journ. Micr. Sci., xlviii, I905, p. 553.

[Annals of Botany, Vo1. XXIV. No. XCIII. January, I9Io.] 
to this extent limits the possible directions of the course of metabolism which ultimately finds expression in structure and form, it is the nucleus which determines and controls the line which is actually followed.

We think the highly important and interesting experiments of C. Herbst ${ }^{1}$ strengthen this view. Herbst found that by starting the development of an ovum on parthenogenetic lines he was able to influence the character of the offspring in the maternal direction-and he has more recently ${ }^{2}$ succeeded in correlating this with the cytological facts-and to show, though indirectly, how large a share the nucleus takes in determining the nature of the individual to which such an ovum will give rise.

It is evident that questions such as these can only be answered by extending the scope of investigation. Whilst the method of direct experiment will ultimately bring us nearest to the goal, the less direct method of observation of those disturbances which often follow on a less artificial deviation from natural conditions cannot fail to be profitable. Hybrids have already yielded results of importance, and recalling the opportunity which presented itself some years ago of investigating a hybrid fern, Polypodium Schneideri, ${ }^{3}$ we determined to inquire into the cytological features attendant on the development of the spores. We hoped that some definite information might thus be obtained which would throw light on certain controversial points connected with meiosis, and especially the prophase stages of the heterotype mitosis. Although the fern has not fulfilled our expectations in this respect, owing mainly to the small size and the large number of the chromosomes, it has nevertheless yielded other results which appear to us to be of sufficient interest to be worth recording.

Polypodium Schneideri was raised by Mr. Schneider in the nurseries of Messrs. Veitch and Sons, Chelsea. It was stated to be a cross between $P$. aureum and $P$. vulgare var. elegantissimum, the latter a beautiful laciniate variety of the common polypody which was found in the wild state. In its general external and anatomical features the hybrid bears out the statements made as to its parentage, and the existence of leaves on which pinnae that have 'reverted' to the simple form of the type in each parent lend further support to the claims made on its behalf. These ' reverted ' pinnae sometimes possess the character of a coarse polypody leaflet, but occasionally they also have the glaucous colour and bloom of the other parent. There is at the present time growing at the Chelsea Physic Garden (where our material has all been cultivated) a plant showing a fine instance of such a 'reversion' in some of its lower pinnae.

Sporangia are produced fairly freely on both the ordinary and the 'reverted' fronds, but in no case have we ever found the spores to be

${ }^{1}$ C. Herbst, Vererbungsstudien, IV. Arch, f. Entwick.-mechanik, Bd. xxii.

${ }^{2}$ C. Herbst, Vererbungsstudien, VI. Arch. f. Entwick.-mechanik, Bd. xxvii.

${ }^{3}$ Farmer, J. B., On the structure of a Hybrid Fern. Ann. Bot., xi. 
capable of germination. The causes for this will become evident later on. Our material was fixed with special precautions, and we found Flemming's and Hermann's solutions, in various strengths, to give the best results. The stains we chiefly employed were Heidenhain's haematoxylin, Flemming's triple, and the Polychrome methylene blue and orange tannin. The latter gave very sharp differentiation, and may be recommended as a valuable addition to the stains in more general use.

In order to elucidate the peculiarities of the hybrid it is obviously necessary to study the meiotic divisions in the parent forms, in order to ascertain whether the influence of either parent preponderates in the cellular structure of the hybrid. It at once becomes evident that there is a great difference between the numbers of the chromosomes in the two species. The haploid nuclei of $P$. aureum contain about 34 (Pl.XVI, Fig. 4), those of $P$. vulgare var. elegantissimum at least $9 \circ$ (Pl. XVII, Fig. I9), and our impression is that this number may' be too low. $P$. vulgare (type) resembles its elegantissimum variety in respect of these numbers, that is, there are about 90 haploid chromosomes (Pl. XVI, Fig. I0) or perhaps somewhat fewer. The exact numbers are of relatively little moment; the comparative differences form the main point of interest. The hybrid plant possesses distinctly more chromosomes than either $P$. vulgare elegantissimum or the type form, but they do not, at least usually, amount to the sum of those of the two parents. They are variable, and commonly range from 95 to 105 , but they do not, in the great majority of cases, amount to I 24 , as they should do if they represented the sum of those contributed by the parents. These facts are of interest in view of the relative numbers that have been given for other hybrids, and we shall discuss their significance later on. We will now proceed to the more detailed description of the features as exhibited by the plants themselves.

\section{POLYPODIUM AUREUM.}

The sporangia of this fern are produced in great abundance. Their development follows the ordinary course, a flattened tapetal cell being cut off from the tetrahedral archesporium; the former then divides tangentially into two layers, the outer of which retains the tabular shape whilst the inner layer becomes glandular in appearance. The sporangium grows faster in the peripheral region than in its central sporogenous portion, and by the time the spore mother-cells are formed and begin to separate from each other they lie as a hollow cluster in the centre of the sporangial cavity. The tapetal cells begin to break down as the nuclei pass into the stage of synapsis, the glairy mass to which they give rise forms a plasmodial nucleated substance bathing the spore mother-cells, and the nuclei of these nutritive cells can still be recognized at much later stages. 


\section{I94 Farmer and Digby. - On the Cytological Features exhibited by}

The details of the meiotic phase were carefully studied in the hope that they might serve to throw light on the processes that obtain during and after synapsis, but they proved too difficult for satisfactory analysis. Cases were often seen which might have been interpreted as due to a lateral approximation of two parallel filaments (P1. XVI, Fig. 2), but it was impossible to feel sure that such an explanation was not illusory. We have, however, seen examples of nuclei which at this stage very closely resembled the excellent figure of Janssens' illustrating the corresponding stage in the spermatocyte of Alytes. ${ }^{1} \quad$ But as we observed numerous other instances in which more than two filaments were apparently involved in the thickened thread, the evidence for approximation at this stage was less cogent than it would otherwise have been. It must also be remembered that during synapsis there is in any event a bunching together of a tangled threadwork, and that it would consequently be singular rather than otherwise if parallelism between some of the threads did not occur. This should be no less true for those filaments which extend from the central tangle to the nuclear periphery than for the rest. Indeed, on merely mechanical grounds, such parallelism might be expected to be found in these threads quite apart from the question of any significance arising such as has been attributed to them on theoretical grounds. We have not succeeded in convincing ourselves that the apparent reduction in the threadwork of the nucleus which certainly does occur at synapsis is to be explained otherwise than as the result of contraction and concomitant thickening of the leptotene filament.

During the very earliest stages of synapsis the cytoplasm in the vicinity of the nucleus begins to exhibit that structural modification termed kinoplasm by Strasburger. It is probable that the extrusion of nuclear substance (Pl. XVI, Fig. I), in the form of granules or droplets of chromatin, is concerned with its appearance; the kinoplasm surrounds the nucleus as a fine feltwork, and recalls the arrangement described and figured by Wilson Smith ${ }^{2}$ for the pollen mother-cells of Osmunda. The spindle in $P$. aureum is very regular, and shortly after synapsis rapidly assumes a bipolar character, in sharp contrast to what happens in the other parent. We examined several other species of the genus, e. g. $P$. guatamalense, Dryopteris, \&c., and found them to resemble $P$. aureum in this respect.

When the spindle is formed (Pl. XVI, Fig. 3), the granules in the cytoplasm, just referred to, are fairly numerous. They are often to be found in the neighbourhood of the spindle poles, but do not seem to exert any appreciable influence on the distribution of the fibres, although some-

${ }^{1}$ Janssens and Willems, La spermatogenèse dans l'Alytes obstetricans. La Cellule, t. xxv, P1. I, Fig. 3.

${ }^{2}$ Wilson Smith, The achromatic spindle in the spore mother-cells of Osmunda regalis. Bot. Gaz., xxx. 
times a few threads may diverge towards one of them here and there. In this respect they are to be contrasted with what occurs in many other plants, e. g. Lilium, Equisetum, \&c.

As the later stages of the division in this species were not traceable in sufficient detail to enable us to add materially to our knowledge of the process, we shall pass on to the consideration of the other plants.

\section{Polypodium vulgare (Type form).}

It was desirable to examine this plant, inasmuch as its variety elegantissimum is one of the parents (or putative parents) of the hybrid. We have already remarked on the large number (about 90) of the haploid chromosomes in this species. In so far as the development of these bodies from the resting nucleus is concerned the process is similar to what obtains in $P$. aureum, but as the larger size of the nucleus (cf. Pl. XVI, Figs. 4 and IO) is more than compensated by the number of the chromosomes themselves, the details of chromosome-formation were not satisfactorily followed. But the character of the spindle is very different in the two plants, and it also exhibits unexpected abnormalities which recur in the varietal form, as well as in the hybrid.

The granules in the cytoplasm, already described for $P$. aureum, are also formed here, and some at any rate are derived from the chromatic constituents of the nucleus. They are seen to be budded off from the nuclear contents into the cytoplasm just as has been described by one of us for Galtonia. ${ }^{1}$

As the nucleus of the spore mother-cell enters on the stage of synapsis, the kinoplasmic nuclear sheath is easily demonstrable, but instead of the bipolar type of spindle a quadripolar (or multipolar) structure (Pl. XVI, Figs. 7,8 ) is differentiated. ${ }^{2}$ The arms (nearly always four in number) are very prominent objects in the cytoplasm, and they persist as well-marked cones which extend from the nucleus to the periphery of the cell. It is not till diakinesis is passing over and the nuclear wall breaks down that the quadripolar arrangement merges into the bipolar one by the fusion and concentration of the poles in pairs (Pl. XVI, Fig. 9).

There are certain features connected with the nuclear contents that are important in relation to the first differentiation of the quadripolar spindle. As the synaptic tangle passes into the more open thread stage which always immediately succeeds it, the chromatic linin is seen to be first less evenly distributed within the nucleus than is more often the case in plants. On the contrary, it is, though rather obscurely, massed at four spots about equidistant from each other just within the nuclear wall. As soon as this becomes

1 See V. Derschau, Max, Beiträge zur pflanzlichen Mitose : Centren, Blepharoplasten. Pringsheim's Jahrb. f. wiss. Bot., xlvi. Digby, L., Observations on 'Chromatin Bodies', \&c. Annals of Botany, xxiii.

${ }^{2}$ Cf. Lawson, A. A., Studies in spindle formation. Bot. Gaz., xxxvi. 
evident, and not before, the kinoplasmic sheath already described is observed to protrude from the surface of the nucleus at these points. In this way the quadripolar structure is initiated. The inference that it arises as the result of a specific influence attributable more or less directly to the chromatic linin seems irresistible. The lines of kinoplasm assume curvatures which unless one is careful may easily lead to misinterpretation. In surface view the appearance is sometimes such as to suggest the existence of a socalled 'Hermann's Spindle'; owing to the fact that in the regions between the cones the fibres form curves which start from the surface of the nucleus (cf. Pl. XVI, Fig. 7, to the left).

Instances also occur where individual threads of the spindle are attracted towards, or perhaps originate from, isolated granules in the cytoplasm; but in this fern, whatever the individual differences may be, a quadripolar (or multipolar) spindle is the rule. We have also found it to occur in the premeiotic archesporial divisions, though not so obviously as at meiosis (Pl. XVI, Fig. 6).

The cones consist each of a dense sheaf of fibres, and these are very ' rigid' in character, as is shown by the fact that a cone may often be seen to cause a bulging out of the cytoplasm (Fig. 7) at the periphery when, through the action of reagents employed in fixing, the cell protoplasm has contracted away from the wall. This 'rigidity' has been observed before and in other plants, and it has been interpreted as the result of a 'growth' of the fibres. We do not share this view of the matter, at least if the word growth is to bear its ordinary meaning; but, as we have already indicated, the whole process seems to us to depend primarily upon repulsive forces developed within the cell. We think the facts support the view that electrical disturbances, and perhaps also phenomena of induction, play the most important part in the formation of these structures, ${ }^{1}$ and whilst they are normally maintained by the continuance of those conditions that were in the first place responsible for their formation, it by no means follows that the cones, when once organized, will lose their identity immediately on the cessation of the operation of the causes which first produced them unless the new conditions are such as to actively render their further continuance impossible. ${ }^{2}$ We have used the term 'kinoplasm' as designating a particular differentiation of the cytoplasm, but we make no assertion as to whether the stuff which this differentiation renders visible really represents a specific substance or not. It is of course easily conceivable that such a substance might exist, but would only become visible, would only become organized, when appropriate conditions were supplied, just as the figure

${ }^{1}$ Lillie, R. S., Am. Journ. Physiol., viii ; also Biol. Bull., iv. See also Gallardo, A., L'interprétation bipolaire de la division karyocinétique. An. del Mus. Nacionale de Buenos Aires, t. xiii, 1906.

${ }^{2}$ Hartog, M., The dual force of the dividing cell. Proc. Roy. Soc., B. 76. 
assumed by iron filings in a magnetic field would differentiate such filings, if present, in a mixture of iron and other dust, provided that the mixture were brought into a suitable magnetic field.

We do not think a question such as this can be really answered by an appeal to stains. The latter act differently according to the physical, as well as the chemical, state of a substance, and it may be that the well-marked staining reactions of 'kinoplasm' ought to be regarded as an expression of physical differentiation (which may be transient) rather than as a proof of chemical difference. On the other hand, it is possible that a chemical change may also be involved in the operation of those very physical conditions that are at the same time responsible for the differentiation itself. The aggregation of the nuclein-charged linin beneath the points of origin of the spindle cones indicates the probability that there exists a causal connexion between the two phenomena, and a suggestion that the immediate cause is electrical in nature appears to be supported by the absence of any direct connexion between the chromatic aggregations and the fibres of the spindle cones, whether at this or at an earlier stage, such as any hypothesis of 'growth' would imply. ${ }^{1}$

As the course of the mitosis advances, the state of aggregation of the chromatic linin disappears, and finally the chromosomes, when fully formed, become uniformly distributed just within the nuclear wall at diakinesis. But the quadripolar character of the spindle persists through these changes. We have already given reasons for not regarding this fact as anomalous; perhaps it may be taken as an expression of a state of 'lag', such as has been regarded as probable by Hartog. ${ }^{2}$ But it cannot be a merely fortuitous circumstance that as the brief stage of diakinesis ends with the dissolution of the nuclear wall (itself a coagulum or a precipitation, and probably to be regarded as due to the interaction or agglomeration of substances present in the colloidal masses of which the cytoplasm and the nucleus respectively are composed, and only lasting so long as certain definite physical conditions persist), the character of the spindle should concomitantly change as well. The cytoplasm, gaining access to the interior of the nucleus, instantly brings about the differentiation of the portion of the fibres which are attached to the chromosomes. At the same time the four cones rapidly coalesce into two opposite bundles, ${ }^{3}$ thus forming at this late stage the bipolar spindle (Pl. XVI, Figs. 8, 9), which is, in the majority of plants, commonly reached at a much earlier stage. And just as the chromatin at the earlier stage appeared to determine the formation of the four or more poles, so now the chromosomes again appear to be the active agents in effecting the resolution of the quadripolar into the bipolar arrangement.

1 We are of course aware that attempted explanations based on the assumption of diffusion currents have been advanced, but these appear to us to rest on no real foundation.

2 Hartog, M., loc. cit.

3 Cf. Lawson, A. A., loc. cit. 
When the chromosomes are fully developed it can readily be seen that they vary in size (Figs. 8, 10). This difference is obvious both at diakinesis, at the equatorial plate stage, and also during the anaphase of the heterotype mitosis. Another feature of this division consists in the somewhat irregular congregation of the chromosomes at the equatorial plate, and the same thing applies to the manner of their separation to their respective poles. It thus often happens that several chromosomes lag behind the rest, though they ultimately all reach their destination. We call attention to this circumstance here because the same irregularities, in an accentuated form, occur in both the varietal and in the hybrid plants.

We have once in this fern met with a simulation of amitosis in the first division of the spore mother-cell (Fig. II). This is of interest, inasmuch as it is fairly common in both the sport and the hybrid, where we shall describe it at some length.

The remaining features of this and the homotype division call for no special remark here, beyond the mention of the fact that the spores, when mature, are commonly fertile.

\section{Polypodium vulgare, var. Elegantissimum.}

This fern produces, as we have already stated, not only the beautifully dissected fronds proper to the variety, but also other leaves which lack, wholly or in part, the laciniate character. They may be said to have 'reverted ' more or less completely to the ancestral type. The 'reversion' may only affect a few pinnae or it may involve the entire frond.

The sporangia are produced on both the varietal and on the 'reverted' pinnae, and germination tests revealed the unexpected fact that those borne on the 'reverted' pinnae were more sterile than those obtained from the laciniate ones. The fertility in either case is, however, a low one, and a large proportion of the spores are seen at a glance to be obviously depauperate and valueless. The development of the sporangia usually runs through a normal course until the mother-cells of the spores are formed, but degeneration commonly sets in during or after synapsis.

During the early stages of prophase the spindle is developed just as in the type form (Figs. 16, 17). The kinoplasmic weft becomes repelled at four or more points on the nuclear periphery, and a quadripolar (or multipolar) arrangement is the result. The poles subsequently fuse, in the manner already described, into a bipolar structure as the nuclear membrane disappears. We may remark that we have observed, in another species of polypody, $P$. tripartitum, a case in which the spindle, though often bipolar, is sometimes quadripolar.

When diakinesis passes over, and the chromosomes are moved towards the equatorial plane, they present a far greater degree of irregularity (Fig. I8) than is the case with the type. By the time that the majority 
have reached the equator some are already to be found at the poles, whilst still others are scattered over the spindle fibres. The impression is conveyed that the irregular chromosomes, which in this fern are not numerous although almost always present, fail in some way to respond to the controlling influence by which the majority are governed. Such a condition indicates a difference in physical and perhaps chemical nature which may well be correlated with the variability, and probably also with the sterility, of the plants now under consideration.

When the chromosomes arrive at the poles they still exhibit that same ' indiscriminate' and confused arrangement which characterized their previous behaviour. They also vary much in size and, so far as we have been able to arrive at a conclusion, they seem to be inconstant in number also. It may be that individuals here and there fail to form bivalents, but when the numbers are so great it is difficult to be sure as to this, and we only feel justified in recording our impression that such is the case.

The degeneration of the cells is associated with a degeneration of the cytoplasm which becomes more and more marked as the spore mother-cells pass through the meiotic phase. This degeneration has been described by Tischler ${ }^{1}$ and others for a number of hybrids in flowering plants, and it is of special interest to encounter it, along with some other characteristics of hybrids, in a form which, though a 'sport', is clearly not of hybrid origin.

A second feature not seldom to be met with during the nuclear divisions of the spore mother-cells of this plant (and, as will appear later, it also occurs in the hybrid as well) consists in a curious form of division nearly resembling amitosis. We have already mentioned that we found a single case in $P$. vulgare, type. It is to be seen in the spore mother-cells produced on both the laciniate and the 'reverted' pinnae, and it may occur in both of the two meiotic divisions. The stage in question usually sets in about the time when diakinesis should pass over to the metaphase, though it may occur at a still earlier period; the nuclear membrane remains intact, and the ordinary spindle is absent or disappears, the nucleus becomes pulled out into a form roughly resembling that of an hour-glass, while the chromosomic contents are numerous, irregular, and small in size. Then the nucleus assumes the condition of a double sac, the swollen portions being connected together by a tube which becomes narrower as the process advances. Fibres then become differentiated in the cytoplasm between the two sacs, and even a cell-plate is formed across this interzonal spindle. When, as is often the case, the sac-like protuberances are not situated symmetrically within the cell, the cell-plate shows corresponding irregularities. Thus it may be well formed on one side of the connecting tube (Fig. 2I), but almost absent from the other. Sooner or later the tubular

1 Tischler, loc. cit. See also Juel, H. O., Beitr. zur Kenntnis d, Tetradenteilung. Pringsh. Jahrb. f. wiss. Bot., Bd. 35 . 


\section{0 Farmer and Digby.-On the Cytological Features exhibited by}

connexion is pulled apart, and the two nuclei thus become completely free from each other, and the cell-plate is formed across the intervening cytoplasm. The final division of the spore mother-cell may also take place in the same manner (Fig. 2I). The whole process is strikingly like that described for hybrid sorts of Syringa (S. chinensis) by Juel, ${ }^{1}$ whose account was confirmed by Tischler, and, as will be seen, it also reappears in the hybrid $P$. Schneideri. But its occurrence is evidently not dependent on hybridity, but probably on a disturbance of the normal intracellular processes such as may indeed be brought about by hybridization, but which may also be connected with more proximate nutritional disturbance, whether produced by unfavourable environment ${ }^{2}$ or by less obvious causes such as are associated with the formation of a 'sport', as in the present instance. For there can hardly be any question of hybrid origin here; the fern was found growing wild, and, besides, there is no other species which seems likely to have contributed to produce its peculiarities, and moreover the type species has long been known to be subject to sporting.

\section{POLYPODIUM SCHNEIDERI.}

This fern is of large and somewhat robust habit. In this respect it recalls the $P$. aureum parent, although, except in some of the 'reverted' leaves, there is otherwise no very close resemblance between the two plants. In the laciniate foliage it is like a very vigorous form of $P$. vulg. elegantissimum. Perhaps it is even still more like the variety known as cambrica. As we have already stated, the 'reverted' parts of the fronds may recall the appearance of either a gigantic polypody leaf, though in the wavy edge, and especially in the glaucous tinge, it approaches more nearly to the aureum type.

Sporangia are freely produced both on the normal and on the 'reverted' leaves. The cells of the sporangia resemble the elegantissimum parent rather than the aureum type in their large size, a feature in which, as will be remembered, the two parents are dissimilar. Fertile spores have never been obtained, either by ourselves or, so far as we have been able to ascertain, by others; the sporangial contents often die away at an early stage of development, and when this occurs the entire sporangium may degenerate, so that even the basal cell situated at the surface of the placenta is involved in the process (P1. XVIII, Figs. 23 and 24).

In other instances development advances as far as the differentiation of the spore mother-cells (Pl. XVII, Fig. 22), and then these may begin to undergo regressive changes. Even the comparatively few spore mothercells that pass through meiosis afford abundant proof that they also

${ }^{1}$ Juel, H. O., loc. cit.

Mr. R. Beer informs us that he has observed this form of nuclear division in pure specimens of Oenothera biennis when these flowered late in autumn, but not in individuals blooming at a more favourable time of the year. 
are for the most part really abnormal, as is shown by the deficiency of cytoplasm which they contain, as well as by the deviations from the usual course of cellular changes which they exhibit. Relatively few of these cells succeed in forming spores, and when they do so the spores themselves are commonly depauperate, and always barren.

We pass now to the description of the cytological features of the development of the sporangia and spores.

In the case of the sporangia which are destined to degenerate early, the nuclei of the cells are seen to change their character and to assume a gelatinous or mucus-like appearance. The cytoplasm diminishes and the cells die away. As we have already said, these lethal changes may involve the basal cell at the periphery of the placental epithelium on which the sporangium is borne. This cell represents the proximal portion of the primordial cell from which, distally, the sporangium is produced.

When the development of the sporangium is not arrested so early, the tapetum is cut off from the archesporium in the usual manner, but it seems never to assume that strikingly nutritive and glandular character so generally associated with this tissue (see P1. XVII, Fig. 22). On the contrary, the cells rapidly become relatively poor in contents. It often happens that the nucleus-or nuclei-may be of large size, but the cytoplasm is small in amount and poor in appearance. The tapetum as a whole breaks down at an early stage, and by the time that the spore mother-cells are passing into synapsis the tapetal contents form a scanty plasmodial nucleated mass within the sporangial cavity. It is evident, we think, that the failure of so many sporangia to advance beyond the synaptic stage is to be directly connected with this weakening of the nutritive function on the part of the tapetum. It often happens that, despite the poverty of the tissue in question, the archesporial cells, up to the isolation of the spore mother-cells and the passage of their nuclei into synapsis, do not show marked signs of deviation from the normal course of development. Possibly their supply of nutrition may be less limited, or the demands on it less exigent, before the characteristic growth of the cell which marks the onset of the meiotic phase with its attendant nuclear changes.

The spore mother-cells which enter on meiosis exhibit a dense synaptic contraction (Pl. XVIII, Fig. 25) in which it becomes impossible to make out the detailed structure, but, as usual, this condition passes over into the open spireme in which the thread is very clear. There appear to be anastomoses between different parts of the thread as a whole, but a little later on the separate chromosomes can be identified. They are, from the time of their first appearance, somewhat abnormal. They give the impression of being badly fixed, but we believe this character is not really due to any such cause but to their actual nature. They are somewhat ragged in outline, and there are great differences in size, as well as of form, between them. 
These peculiarities persist throughout their existence, and are very strongly marked in the later stages of diakinesis. As regards numbers they exceed those of the corresponding nuclei of either parent, though careful counting has convinced us that there is no very great constancy in the numbers actually present in the nuclei of this plant. We have already alluded to this circumstance in connexion with the other species, but it is far more obvious here. The chromosomes, so far as we could estimate them, vary from about 95 to 125 , though about 95 to 105 is the more common range. The striking difference in individual size (see Figs. $30,3 \mathrm{I}, 3^{2}$ ) is a point of some interest, inasmuch as it might be taken to indicate that the larger ones represented bivalents whilst the smaller ones constituted the univalent remainders which had failed to pair. This hypothesis would fit the fact that the chromosomes contributed by the two parents respectively are numerically different (about 34 in P. aureum and 90 or more in P. vulg. elegant.). But in any case such unions to form bivalents must at best be irregular, and we entirely failed to find anything which would justify us in asserting that there were 34 bivalents or indeed any other constant number of larger chromosomes which could be really identified as such. Certainly there is no such regularity in this instance as exists, for example, in the hybrid Drosera according to Rosenberg. We would, however, point out that this seems to us to be in no way surprising. Indeed it is difficult, on the assumption that the chromosomes ordinarily contributed by the male and female parent respectively are to be regarded as homologous, and therefore destined to pair at meiosis, to see how any such homology can exist at all when the numbers are different in the two parents. For it is, in the first place, extremely improbable that any single one of those of the more numerous lot can be equivalent to any single one of the less numerous group, and it is obviously impossible that there can be any close resemblance between the whole of the lot comprised in the smaller number and an equal number (less than the whole) of the larger set furnished by the other parent. In many of these cases there are, as in the Drosera plants under consideration, twice as many chromosomes contributed by one parent as by the other. It seems not unlikely that the double number of the one has arisen by a division of the individual chromosomes in the ancestor of $D$. longifolia which have thenceforth remained distinct. If this has occurred by a transverse fission, then we might expect one chromosome derived from the (IO) parent (D. rotundifolia) to unite at meiosis with two chromosomes from the (20) parent (D. longifolia), so that there would be practically ten bivalents produced. If, however, it be argued that the twenty chromosomes of D. longifolia have arisen not by transverse, but by longitudinal fission, and that they have, in the absence of hypothetical 'regulative' processes, persisted unchanged, and so have come to be characteristic of the species in question, we are thereby driven to the 
admission that the whole case for individuality and differentiation amongst the chromosomes rests on a far more insecure and speculative foundation than, on other grounds, would be generally admitted. We do not urge these considerations in any sense as suggesting that we doubt the statements that have been made respecting the process in Drosera. Our only motive for alluding to this case is because it is, from the relatively few number of the chromosomes, a much more favourable case than is our plant for ascertaining the facts, and at the same time to indicate that, in our opinion, the special importance which has been attached by some writers to the course of events in Drosera can nevertheless hardly be maintained as being of general application. Furthermore, that there are also, as it seems to us, obstacles which from a theoretical standpoint make the interpretation which has been put on the pairing of the chromosomes in this and in similar cases difficult of acceptance.

The important results which have recently been published by Gates, ${ }^{1}$ as the result of his investigations on hybrid Oenotheras, prove that there are other factors connected with the possible modes of chromosome distribution of the nature of which we are as yet practically ignorant. Gates finds that the hybrid Oenothera lata $\times 0$. gigas has $2 \mathrm{I}$ chromosomes in its premeiotic cells. At meiosis this premeiotic number reappears, owing to the failure to pair on the part of the chromosomes, and finally each of the resulting nuclei receives as nearly as possible the half of this number, i. e. either Io or II respectively. There are irregularities also, but these are of no consequence for our present purpose. The feature around which our interest centres is that despite the fact that the two parents contribute different numbers of chromosomes, an equal, or almost an equal, number are distributed to each of the daughter-nuclei in the heterotype mitosis. That is to say, the distribution is not the result of ' a pairing and separation of homologous chromosomes of maternal and paternal origin, but the segregation tends to be into two numerically equal groups'. ${ }^{2}$ These results are in harmony with those we have obtained in Polypodium Schneideri, for the chromosomes, whether they are bivalent or not, are about equally distributed between the two daughter-nuclei at the heterotype mitosis, in spite of the fact that the share, numerically speaking, which is contributed by the two parents respectively is so markedly dissimilar. We are far from desiring to suggest that these results affect, at any rate necessarily, the views which are entertained by many respecting the allelomorphic distribution of chromosomes in a normal plant. It may well be that the peculiarities that characterize the behaviour of the chromosomes in these hybrids are directly correlated with their sterility. But however this

${ }^{1}$ R. Ruggles Gates, The behaviour of the chromosomes in Oenothera lata $\times 0$. gigas. Bot. ${ }^{2}$ Ibid., p. I95. 
may be, the facts cannot be without importance as we gradually arrive at a position which may enable us to formulate a coherent theory of the mechanism which is responsible for the distribution of the chromosomes to the daughter-nuclei at mitosis.

Before considering the various aberrant features which the chromosomes of $P$. Schneideri exhibit during the heterotype mitosis, we may proceed to describe the mode of spindle-formation in these cells. As in the common polypody, the spindle is usually quadripolar instead of bipolar. It is, however, never so well developed as in the parent species (cf. Figs. 26, 27 , with 16,17 ), and this fact is to be correlated with the relatively poor amount of cytoplasm which, as we have already said, is present in the cells. Probably the abnormal character of the nuclear metabolism may also act as a contributory cause. The first indications of spindle-formation are to be seen during the later stages of the thick spireme, just when what we have elsewhere termed the 'second contraction' is setting in. The fact that sometimes its inception may apparently be deferred to even later stages is perhaps to be attributed to the difficulty of recognizing the earliest stages in cells that under any circumstances do not form the achromatic structures as distinctly as in the majority of allied forms.

The kinoplasmic differentiation around the nucleus can be made out, though often with difficulty, at earlier stages. Then there occurs a similar aggregation of the chromatic linin such as we have described above for the other ferns. The chromatic linin forms a bunched mass (Figs. 26, 27), often very prominent and striking, just beneath the nuclear wall, and at several spots. The kinoplasm on the outer side of the nucleus, at places exactly corresponding to these aggregations, is repelled, or at any rate diverges there, from the surface of the nucleus. It differentiates into spindle fibres which, though feebly developed, ultimately traverse the cytoplasm to the periphery of the cell, and end in denser masses of protoplasm just beneath the cell-wall. Sometimes there are clusters of granules at these spots, but the cytoplasm also contains other granules distributed in its mass. The appearance of the fibres in surface view is often very remarkable, as is shown in Pl. XVIII, Fig. 29. It may happen, however, that the spindle is not quadripolar but bipolar at these stages, though this is not of frequent occurrence. The nuclear wall remains intact till diakinesis, and at this stage the quadripolar arrangement of the chromosomes is often very striking. At other times the chromosomes are apparently grouped in three clumps (Fig. 32), two being smaller than a prominent central group.

As the wall of the nucleus breaks down, the spindle immediately becomes bipolar, but the three or four chromosome clusters may persist. Such cases lead to very irregular figures, as the two smaller sets move at once towards the poles, whilst the more central group or groups take some time to point off to their respective destinations. 
A peculiar feature, already observed in $P$.vulg. var. elegantissimum, and once also in the typical $P$. vulgare, is to be seen in the nuclei which go through division without the disappearance of the nuclear wall (Pl. XVIII, Figs. 33, 34). Such examples, as already pointed out, at first sight suggest amitosis, but the fact that the chromosomes are quite distinguishable serves to indicate the need for caution in drawing this conclusion respecting them. As a matter of fact, they are more properly to be described as imperfect mitoses-imperfect inasmuch as the nuclear wall does not become destroyed. The whole nucleus is pulled out like a sac, and this then is distended at its two ends. The ends gradually receive a moiety each of the chromosomes, which are sometimes much smaller and shorter than in the normal mitoses, or, if the process has set in earlier, they may be in the long thread stage. The two end-sacs are for a time connected by a tubular bridge which gradually becomes more and more attenuated and finally is empty of chromosomes, these having passed to the distended ends. In the cytoplasm which lies between the latter the interzonal spindle fibres are developed. These are often somewhat irregular, but they are invariably present, and when the tubular bridge is centrally and symmetrically placed in the cell, it is seen to be equally surrounded by the fibres. When, however, as is often the case, the tubular connexion is excentrically placed, it may happen that the interzonal fibres are absent or sparsely developed on the outer side. The whole process seems to us to afford a confirmation to the view that the fibrous system of lines is due to an indirect influence of the nuclear contents on the cytoplasm and to be dependent on the induction of a state of stress as the result of the chemical changes going on in connexion with the nuclein transformation that is taking place. At any rate there is here no question of any kind of open communication between the nuclear contents and the cytoplasm such as accompany an ordinary mitosis. A cellplate is formed across the interzonal fibres, and sometimes this seems as if it were about to nip the tubular connexion into two parts.

The homotype mitosis (Fig. 35) calls for no special comment beyond the statement that this curious form of division may also occur in connexion with it; indeed it seems to do so generally when it has occurred in the preceding (heterotype) mitosis.

During the reconstruction of the normal daughter-nuclei the cytoplasm is seen to contain numerous granules which are coloured by dyes that are capable of staining chromatin. These are very well known to all who are familiar with the details of karyokinesis, and there is some doubt as to their origin. We have been able to trace at any rate some of them in these plants quite definitely to a nuclear source. They are given off (Fig. 35) by the vesiculating chromosomes as buds which pass out from the nucleus into the cytoplasm (cf. Pl. XVII, Fig. I2), in somewhat the same way as occurs at the commencement of the division (Pl. XVI, Fig. I), Whether 
this elimination of chromatic substance is to be regarded as always possessed of the same significance seems to us to be doubtful, but the facts before us are not as yet sufficient to enable us to usefully discuss the question at the present time. It may well be that we are here dealing with matters destined to throw light on the bodies known as chromidia, but overmuch speculation in proportion to the amount of positive knowledge has already grown up around these matters, and it seems premature to add to it on this occasion.

\section{General Conclusions.}

The main points of general interest which appear to us to emerge from the study of the ferns as detailed in the foregoing account relate to the formation of the spindle and to the behaviour of the chromosomes in the sports and hybrid respectively.

The mode of differentiation of the kinoplasmic weft around the nucleus supports the view long ago advanced by one of us to the effect that this is to be regarded rather as a specialized and temporary arrangement in the cytoplasm than as indicating a permanent substance in the cell. Strasburger, to whom we are indebted for the clear recognition of the differentiation in question, also now holds that no absolute distinction between kinoplasm and the cytoplasm can be maintained, although so long as it does exist the protoplasm, thus distinguishable, is the seat of metabolic change of a nature often very definite in character.

The spindle fibres are clearly produced at the expense of such cytoplasm in the cases studied here, and indeed more clearly so than is frequently the case in other plants. We think that the particular mode of the formation of the spindle points strongly in the direction of its originating as the result of electrical disturbance within the colloids of which the cytoplasm is made up. We have shown how it arises just above the aggregations of chromatin-containing linin, and we believe that a real causal relation is here indicated. It will be remembered that one of the characters of albumin is its capacity of absorbing, or otherwise associating with itself, dissociation products which may carry electrical charges of different sign. ${ }^{1}$ The apparent magnitude of the observed results is to be attributed, at least in part, to the smallness of the field (the cell) in which the forces are operating.

The view that the spindle owes its existence as well as its character to electrical conditions has been repeatedly advocated. In recent years Hartog ${ }^{2}$ has endeavoured, by working models of an ingenious form, to show that the poles of the spindle may be compared with unlike poles of a magnet, and that the curved system of lines assumed by the achromatic fibrils are to

\footnotetext{
${ }^{1}$ See Lillie, R., On the differences in the electrical connexion of certain free cells and nuclei. Am. Journ. of Physiol., viii.

${ }^{2}$ Hartog, M., The dual force of the dividing cell. Proc. Roy. Soc., B. 76.
} 
be regarded as approximately representing the position of the lines of force in a magnetic field between such unlike poles. Gallardo, ${ }^{1}$ on the contrary, has argued that the difficulties that must underlie the assumption of unlike poles under the conditions in which they could exist in the cell are wellnigh insuperable. It is difficult to see how they could be kept asunder, much less to understand how they could actually move still further apart. ${ }^{2}$ Gallardo's contention is that the apices of the spindle represent not unlike but like poles, and he regards them as due to an inductive effect, dependent on the charge carried by the contents of the nucleus. At the same time he remarks that there are cases in which the achromatic fibres are entirely differentiated in the cytoplasm under conditions in which the nucleus is excluded from all share in the process. Such an example is afforded when, by the agency of drugs, the spindle fibres are caused to appear in cells from which the nucleus has been removed. In this case Gallardo thinks that the poles are really unlike. ${ }^{3}$

It seems improbable that there can exist so fundamental a difference in this respect, and we are ourselves of opinion that the solution of the problem will be found to lie in the proof that the poles are always similar to each other and of opposite sign to that of the acid nucleus. The matter is complicated by the colloidal nature of the material in which the process is going on, and the state of lag, so well insisted on by Hartog, may well account for much that is otherwise anomalous. We recognize that the so-called 'Hermann's Spindle', as well as those other instances in which the centrosomes diverge from each other, although the connecting fibres form a convergent system of curves, are difficult cases. But the remarkable manner in which the sheaves of fibres in these ferns diverge from the proximity of the chromatin-charged linin, and are so repelled by each other that they press out equidistantly at the periphery of the cytoplasm, seems to us to provide an almost overwhelming support for the hypothesis that the linin with its contained chromatin, by virtue of the chemical changes involved in its metabolism, has brought about an electrical condition of opposite sign similar in each of the spindle-cones formed from the substance of which the kinoplasm is made up. This hypothesis also is in harmony with the fact that the disappearance of the nuclear membrane is closely associated with the spreading of the chromosomes beneath it just before their retrogressive movement to the equator, whilst the spindle poles have shifted away from the nuclear surface. The change of size of the nucleus,

${ }^{1}$ Gallardo, A., L'interprétation bipolaire de la division karyocinétique. An. Mus. Nac. de Buenos Aires, t. xiii.

${ }^{2}$ The subsidiary hypotheses which have been advanced to explain the spindle mechanism on the assumption of unlike poles do not appear to us to be convincing.

${ }^{3}$ In a paper just published in the Archiv f. Entwickelungsmechanik (vol. xxviii) Gallardo has given up this view, and asserts that the sign is always similar in the cytoplasm, i. e. electropositive. 
so obvious during the progress of mitosis, a change which has often been interpreted as indicating alteration in osmotic relations, or, less precisely, has been ascribed to growth changes, seems to us to find a less strained explanation when regarded as due to change of electrical state than in any other way. It has been shown that the size of the nucleus may alter during the prophase of division, and that this may be correlated with the changes in the chromatin. Further, that the 'growth' is not regular, but may oscillate in the plus and minus directions. And it cannot escape notice that the periods of maximal size coincide with the spreading out of the chromatin beneath the nuclear wall, that is, with conditions that tend to lower the surface tension of the membrane, or even to bring about its disappearance altogether, by resolving the coagulated state to which it almost certainly owes its existence. The time has admittedly not yet arrived when it will be possible to give an explanation of these cellular changes that will prove completely satisfactory from a physical point of view. We have still much to learn concerning the modifications imposed by the physical and other properties of the colloids ${ }^{1}$ in which the chemical disturbances that are bound up with the changes of form and with the genesis of structures such as those we have been considering are taking place. For example, as Hartog pointed out, the lines of force in a magnetic field, ${ }^{2}$ although they may be mapped out by the arrangement of those cell constituents which, as he says, are more 'permeable', may be themselves abolished or otherwise modified, without a simultaneous effect becoming at once manifest in the 'chains' formed of material particles which are relatively immobile, and tend to retain any particular arrangement (in this case approximately that of lines of force) in which they have been cast until, by the action of other forces, they are compelled to assume new positions.

If we now turn our attention to the behaviour of the nucleus, we find the infertility of the varietal form as well as of the sport to be intimately related to degenerative changes in the nucleus. We have seen how degeneration may set in at an early stage in the history of the development of the sporangium, and that the lethal processes are first visible in the nucleus. The cytoplasm also is very characteristically altered, and gives the impression of being starved. The same is true of the separated spore mother-cells, except that in them the starvation in the cytoplasm is more definite, doubtless owing to the poor nutrition consequent on the failure of the tapetum to develop properly. It is at any rate quite clear that the normal relations between the cytoplasm and the nucleus have become

1 e.g. the adsorption of ions, dissociation or association products, on the colloidal surfaces.

2 It may be as well to point out that there can be no question of the existence of magnetic forces in the cell. The problem is one of electrostatics, and Hartog showed he was fully aware of this; cf. his paper on 'The dual force of the dividing cell' in Science Progress, 1907. 
abnormal, and it may be that the disturbance of these relations, the upsetting of the Kernplasma-relation, lies near the root of the matter.

But it is of course evident that this does not really explain anything, for what we want to know is just what it is that disturbs these normal relations. It is certainly not merely hybridism. The hybrid is indeed more sterile than the sport, but the phenomena are of the same order in the two cases. We find the same early degeneration in both, the same 'tubular' nuclei simulating amitosis, the same irregularity in the distribution of the chromosomes on the heterotype spindle. We feel that it is of little use at present to endeavour to give explanations which can only rest on a very insecure base. But it is at any rate clear that the sterile 'sports' demand far more attention than has hitherto been paid them, and we confidently anticipate that they will furnish important clues to the understanding of the causes of sterility in hybrids. Many of the remarkable deviations that are so characteristic of the cells, and especially of the nuclei, in malignant neoplasms, are also to be encountered in the aberrant cells of these sports and sterile hybrids. Whether the underlying causes are similar is still to seek, but we think that there is an interesting field of inquiry in this direction, and one well worthy of investigation. As far as the immediate future is concerned, what is required is a greatly extended knowledge of the plain facts.

We do not propose to discuss the questions that arise in connexion with the mode of formation of the heterotype chromosomes further than we have already done, but reserve this to be dealt with in a future communication now on the way towards completion.

\section{SuMMARY.}

I. The evidence from the study of the cytology of Polypodium Schneideri is consistent with the view that it is of hybrid origin, although it is not very conclusive if taken by itself.

2. The nuclei of $P$. aureum are about two-thirds the diameter of those of $P$. vulgare and its var. elegantissimum. The number of chromosomes in $P$. aureum is about $34-36$, in $P$. vulgare about 90 , and there are about the same number in the variety elegantissimum. In $P$. Schneideri, the hybrid, there are variable numbers, the range lying between 95 and 125 .

3. The sporangia are apt to produce a large proportion of abortive spores in var. elegantissimum, and in the hybrid no fertile spores have been found. This sterility is to be associated with the degenerative changes in the cytoplasm, and these become especially acute at meiosis. The nuclear apparatus also appears to be, at least in part, responsible for the failure to form fertile spores.

4. The achromatic spindle in $P$. aureum and some other species is 
bipolar from its early appearance, in P. vulgare and its var. elegantissimum it is quadripolar in the great majority of cases, in the hybrid it is either bipolar or quadripolar, more commonly the latter.

5. The spindle is formed from a differentiation of the cytoplasm (kinoplasm), and it is influenced in its distribution within the cell by the aggregation of the chromatic linin within the nucleus. This is especially seen in the cases of quadripolar spindle formation. Electrical conditions are believed to be concerned in the spindle formation.

6. Chromatic droplets are ejected from the nucleus into the cytoplasm during the early stages of the heterotype mitosis, and also during telophase at other mitoses. It is left an open question as to whether this phenomenon always implies the same processes.

7. Nuclear divisions resembling amitosis occur frequently in the hybrid, but they also occur, though far more rarely, in $P$. vnlgare (type) and in its variety elegantissimum. These divisions are examples of imperfect mitoses, and are brought about by the failure of the nuclear wall to disappear at the end of diakinesis.

8. Much irregularity as to pairing of the chromosomes to form the bivalents exists in the hybrid plant, and also, though less obviously so, in $P$. vulgare var. elegantissimum.

9. The processes that lead to depauperation of the reproductive cells, and ultimately to sterility, in hybrids are encountered in certain 'sports, which also exhibit sterility in a marked degree'.

\section{EXṔLANATION OF PLATES XVI-XVIII.}

\section{Illustrating Professor Farmer and Miss Digby's paper on the Cytological features exhibited by} certain varietal and hybrid Ferns.

All the figures, with the exception of Figs. 22,23 , and 24 , were drawn with the camera lucida under a $2 \mathrm{~mm}$. apochr. hom. imm. Zeiss, N.A. I.40 with comp. oc. $18 . \quad \times 2250$.

Fig. 22 was drawn with the camera lucida under a $3 \mathrm{~mm}$. apochr. hom. imm. Zeiss, N.A. I.40 with comp. oc. $6 . \quad \times 498$.

Figs. I-5. Polypodium aureum.

Figs. 6-13. Polypodium vulgare.

Figs. 14-18. Polypodium vulgare var. elegantissimum.

Figs. I9-2I. Polypodium vulgare var. elegantissimum (' reverted').

Figs. 22-34. Polypodium Schneideri.

PLATE XVI.

Fig. I. Polypodium aureum. Early heterotype prophase in the spore mother-cell nucleus. 'Chromatic droplets' are being given off from the nucleus; some lie free in the cytoplasm, whilst others are still attached to the nuclear contents by fine connexions. $\times 2250$. 
Fig. 2. Three adjacent spore mother-cells whose nuclei show successive stages in the withdrawal of the network from the nuclear periphery; the first indication of the preparation for 'synapsis'. $\times 2250$.

Fig. 3. The chromosomes are coming out of second contraction. Note the bipolar spindle, and the massing of the chromosomes at the two parts of the nuclear periphery which will be invaded by the fibres. $\times 2250$.

Fig. 4. Polar view of a heterotype equatorial plate. $\times 2250$.

Fig. 5. Heterotype equatorial plate. $\times 2250$.

Fig. 6. Polypodium vulgare. Archesporial nucleus in prophase showing the premeiotic spindle origin. One of the spindle cones is distinctly bilobed. Note the granules towards which many of the fibres converge. $\times 2250$.

Fig. 7. Fully formed chromosomes. The four spindle cones are in the same plane. $\quad \times 2250$.

Fig. 8. The fibres have invaded the nucleus, and the chromosomes are becoming arranged on the spindle. Two of the spindle cones have come together, the other two are still wide apart. $\times 2250$.

Fig. 9. Slightly later stage in which the quadripolar spindle has become decidedly bipolar. $\times 2250$.

Fig. 10. Polar view of a heterotype equatorial plate. $\times 2250$.

Fig. II. Aberrant mitosis, the result of an incomplete first meiotic division. The narrow bridge joins the two sac-like nuclear extremities. The interzonal spindle fibres are clearly to be seen. $\times 2250$.

\section{PLATE XVII.}

Fig. I 2. Polypodium vulgare (continued). Telophase of the first meiotic division showing the extrusion of 'chromatic droplets', some of which are still joined to the nuclear chromatin by conspicuons threads. $\times 2250$.

Fig. I3. Nucleus of tetrad after the second meiotic division. Extranuclear ' chromatin droplets' are in direct connexion with the nuclear threadwork. $\times 2250$.

Fig. I4. Polypodium vulgare var. elegantissimum ('reverted'). Nucleus of tetrad showing 'chromatin droplets' still attached. $\times 2250$.

Fig. I 5. Nucleus going into synapsis. A stage slightly later than Fig. $2 . \quad \times 2250$.

Fig. I6. Nucleus having passed through the 'hollow spireme' stage is passing into second contraction. There is a marked massing of the spireme at the areas where the spindle radiations are in contact with the nucleus. $\times 2250$.

Fig. I7. A later stage showing the increased massing of the chromatin. $\times 2250$.

Fig. 18. Heterotype diaster. The chromosomes pass to the poles in an irregular manner. $\times 2250$.

Fig. 19. Polypodium vulgare var. elegantissimum (from varietal leaf). Polar view of a heterotype equatorial plate. $\times 225^{\circ}$.

Fig. 20. Aberrant form of the first meiotic division, giving off droplets of chromatin. The cellplate is incomplete. $\times 2250$.

Fig. 2I. Aberrant nuclei of the second meiotic division. These nuclei will break apart as the tetrads mature. $\times 2250$.

Fig. 22. Polypodium Schneideri. General view of a sporangium with its spore mother-cells. Note the scanty tapetum. $\times 49^{8}$.

\section{PLATE XVIII.}

Figs. 23 and 24. Polypodium Schneideri (continued). An abortive sporangium dying back to the placenta (two drawings of the same sporangium in consecutive planes). $\times 498$.

Fig. 25. Nucleus passing into synapsis. A stage between Figs. 2 and $15 . \quad \times 2250$.

Fig. 26. Nucleus coming out of the 'hollow spireme' and beginning to prepare for the second contraction. There is a slight concentration of the spireme towards the spindle fibres. $\quad \times 2250$.

Fig. 27. Chromosomes coming out of second contraction. The spindle fibres are feebly developed as compared to those of $P$. vulgare and to the variety elegantissimum at the corresponding stage. $\times 2250$. 


\section{Farmer and Digby.-Cytological Features of Hybrid Ferns.}

Fig. 28. Slightly later stage. Again the spindle cone is relatively inconspicuous. $\times 2250$.

Fig. 29. Superficial view of a quadripolar heterotype spindle. Many of the fibres are in connexion with granules. $\times 2250$.

Fig. 30. Formation of an irregular heterotype spindle. $\times 225^{\circ}$.

Fig. 3r. Quadripolar heterotype spindle. Only three limbs are seen, the fourth lies in the next section. $\times 225$.

Fig. 32. Typical heterotype spindle of this plant, showing the large collection of chromosomes at the equator, and the smaller groups at either pole. The spindle fibres are few. $\times 2250$.

Fig. 33. Aberrant heterotype nuclear division. $\times 2250$.

Fig. 34. Aberrant heterotype nuclear division, but somewhat later stages; the chromosomes are swelling and losing their sharpness. The axis joining the two nuclei is not in the focal plane, hence the apparent breadth of the tubular connexion. $\times 2250$.

Fig. 35. Second meiotic division of a fairly normal character, which is of rare occurrence in P. Schneideri. Note the 'droplets' and the belated chromosomes. $\quad \times 2250$. 
Annals of Botany,
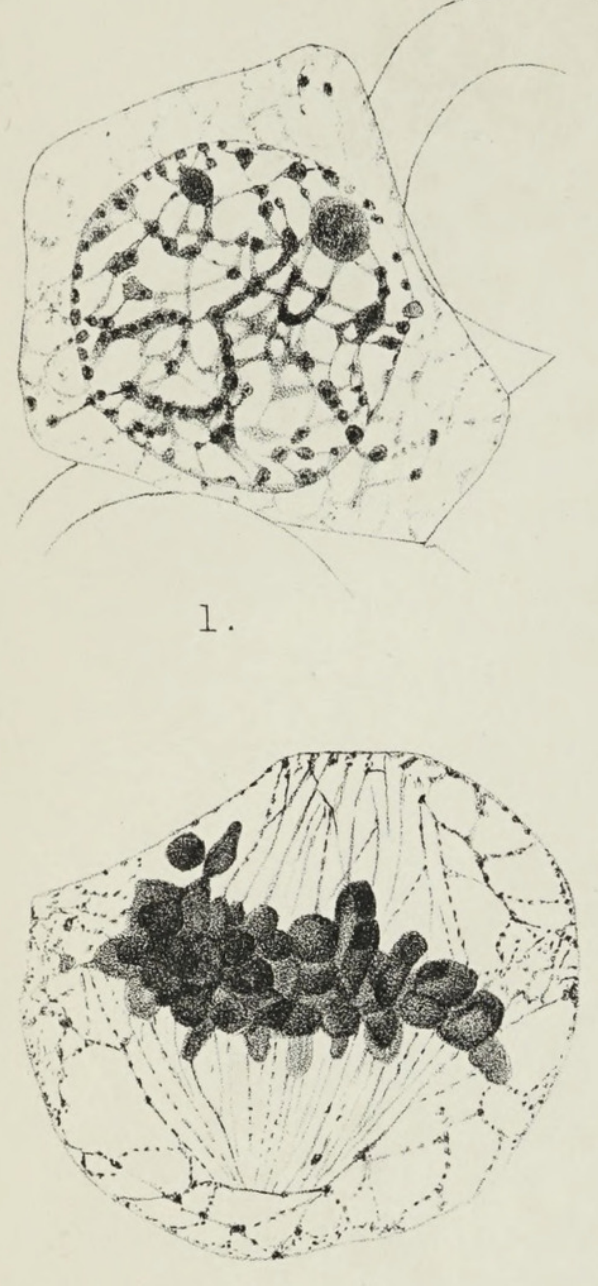

5

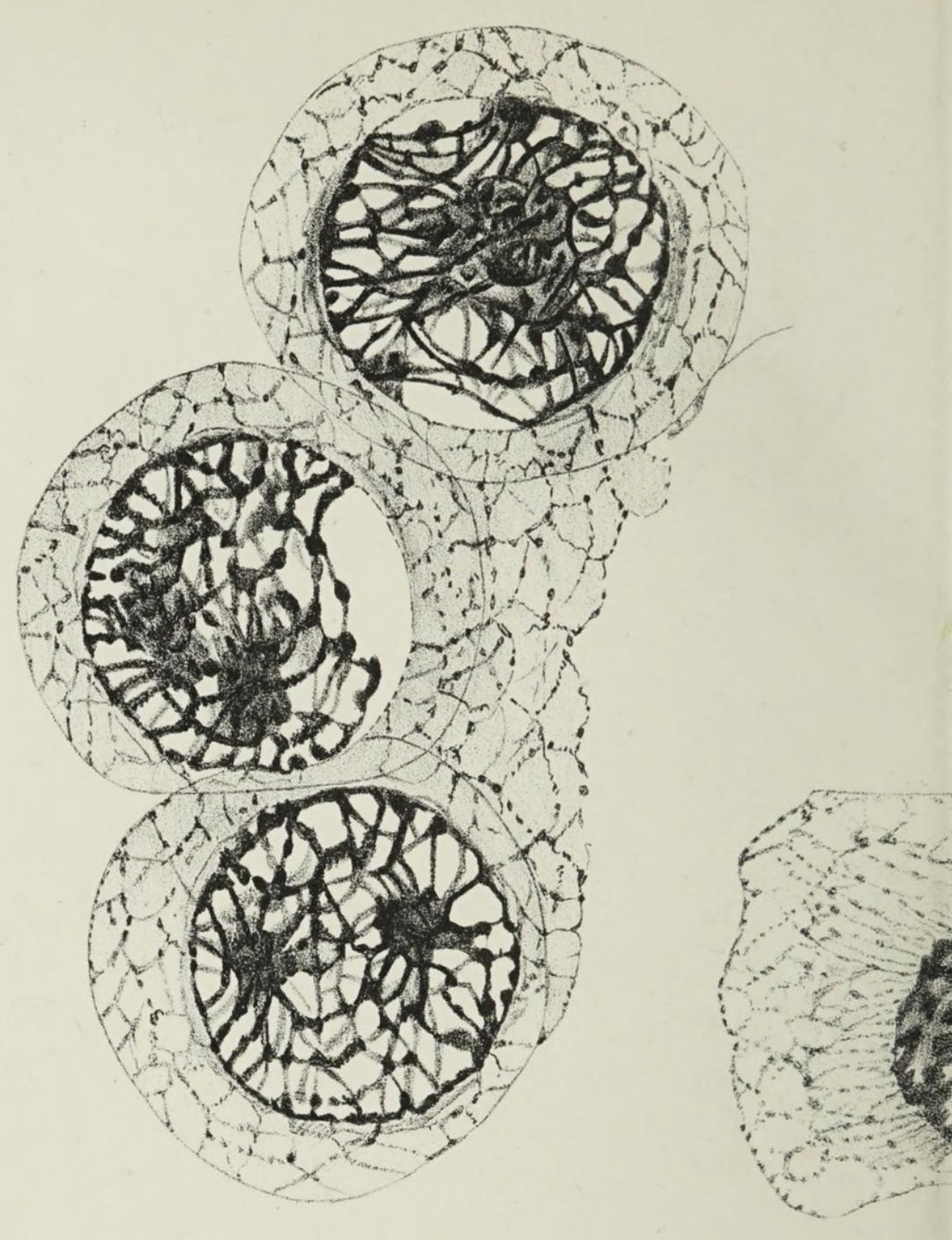

2.

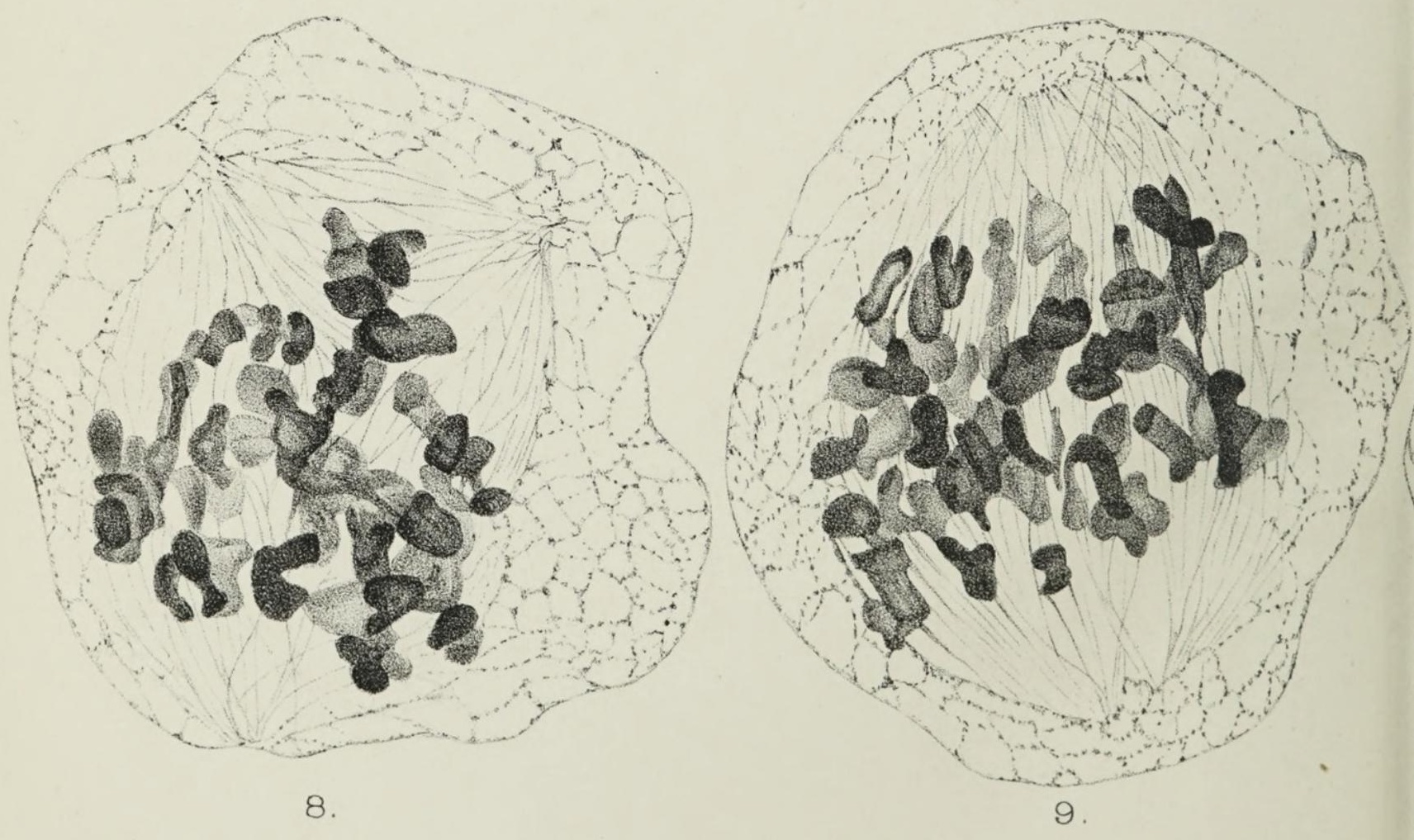

FARMER \& DIGBY - CYTOLOGY OF HYBRID FERN. 

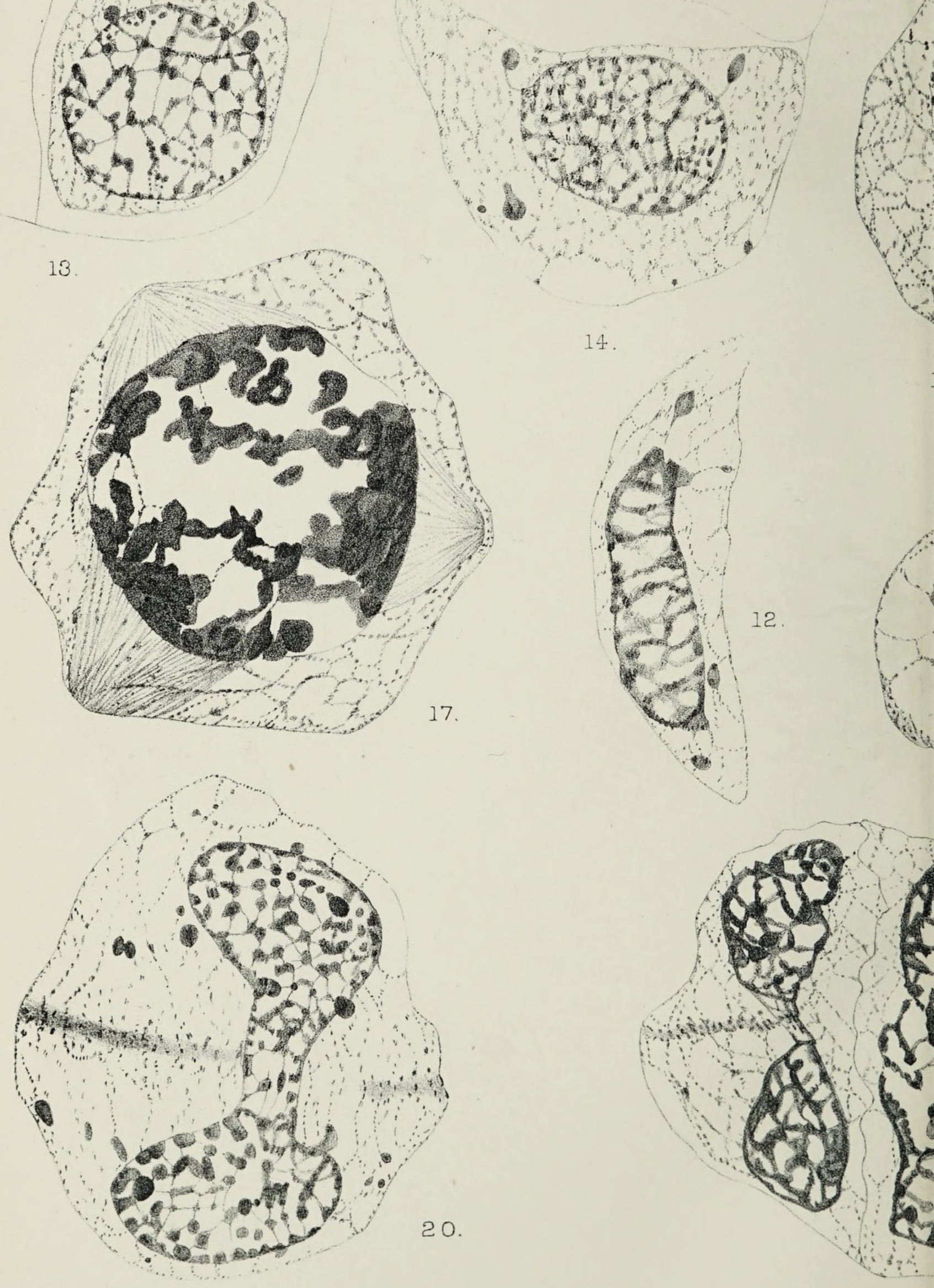
Annals of Botany,
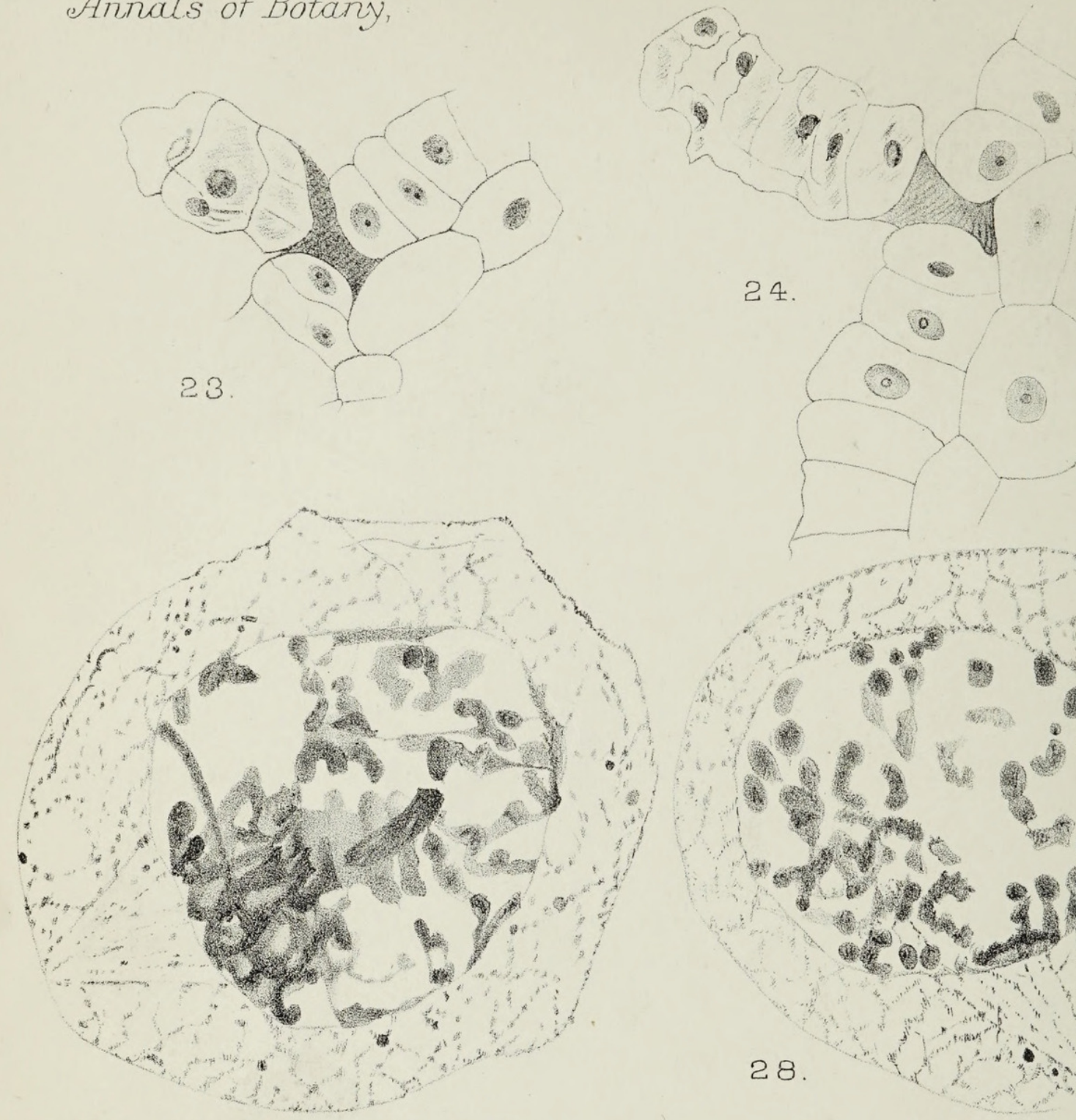

24

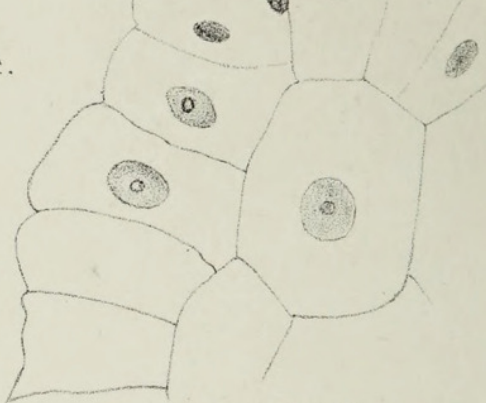

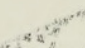

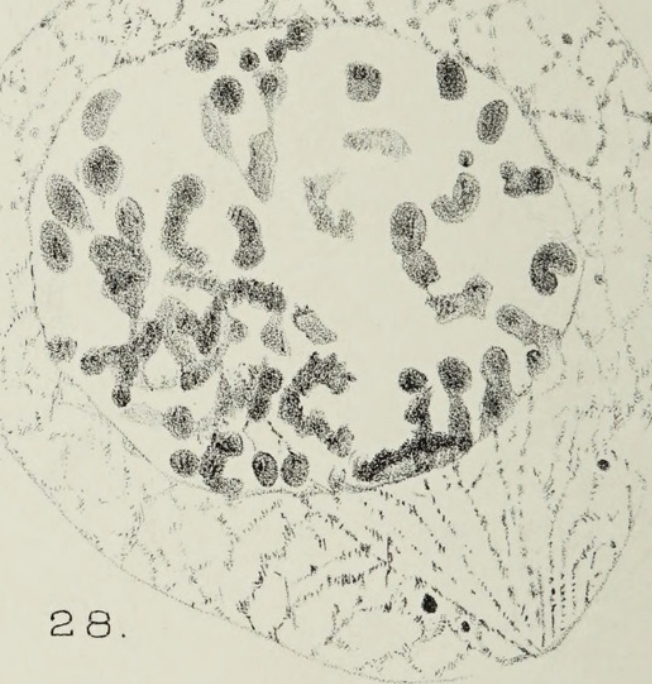

27.
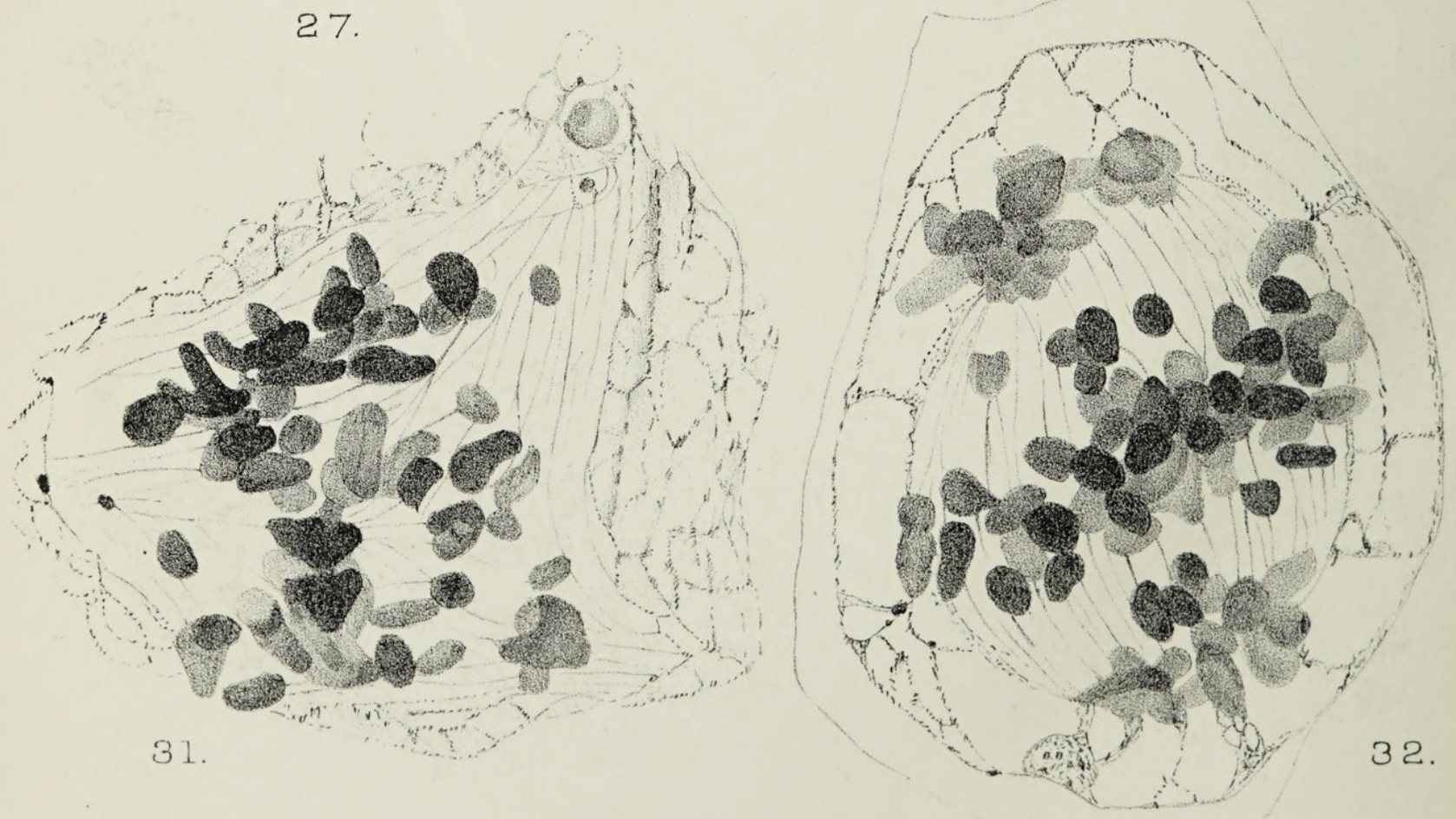

FARMER \& DIGBY C CYTOLOGY OF HYBRID FERN. 

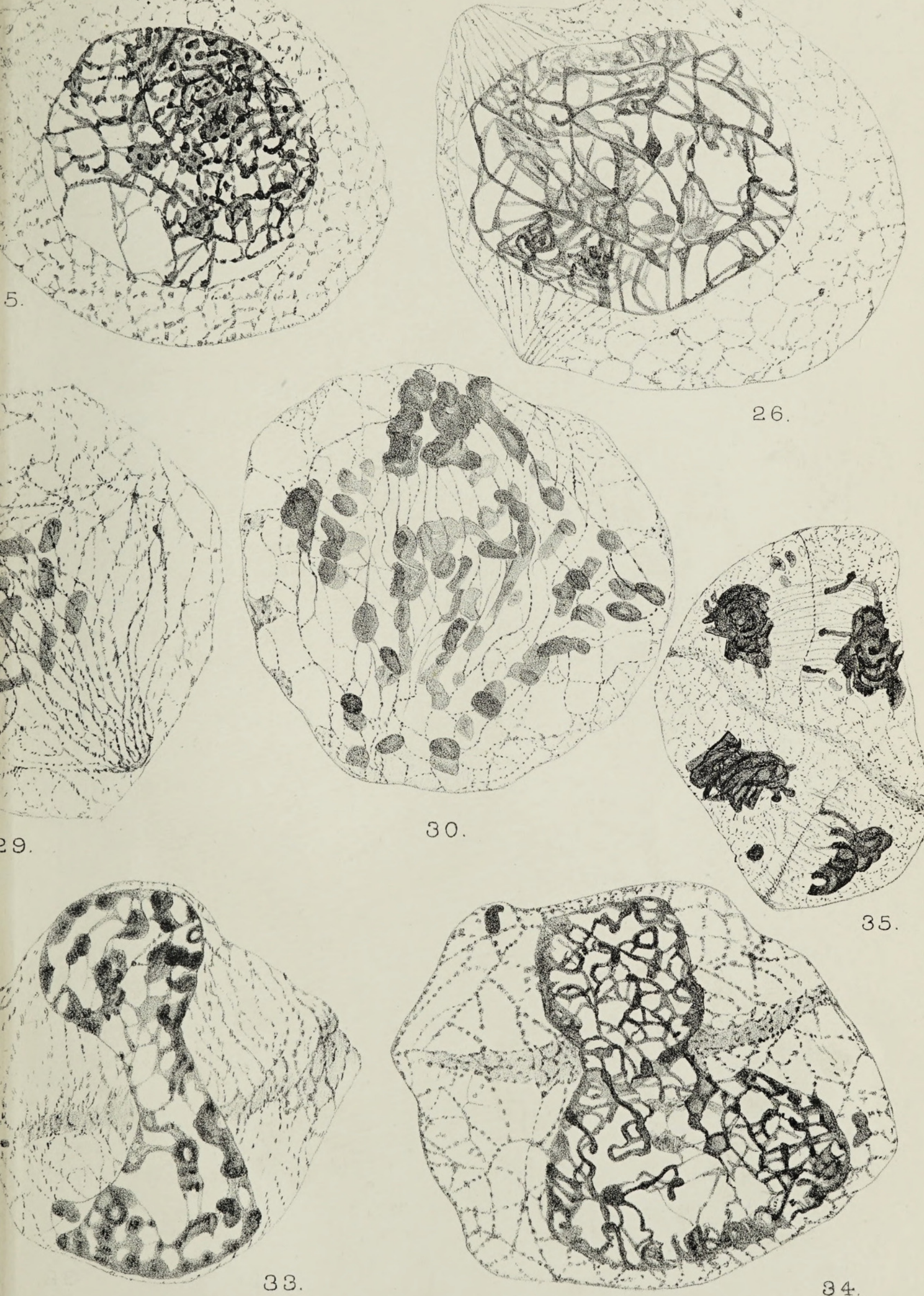


\section{$2 \mathrm{BHL}$ Biodiversity Heritage Library}

Farmer, J. B. and Digby, Lettice. 1910. "On the cytological features exhibited by certain varietal and hybrid ferns." Annals of botany 24, 191-212. https://doi.org/10.1093/oxfordjournals.aob.a089255.

View This Item Online: https://www.biodiversitylibrary.org/item/262605

DOI: https://doi.org/10.1093/oxfordjournals.aob.a089255

Permalink: https://www.biodiversitylibrary.org/partpdf/319766

\section{Holding Institution}

New York Botanical Garden, LuEsther T. Mertz Library

\section{Sponsored by}

BHL-SIL-FEDLINK

\section{Copyright \& Reuse}

Copyright Status: Public domain. The BHL considers that this work is no longer under copyright protection.

This document was created from content at the Biodiversity Heritage Library, the world's largest open access digital library for biodiversity literature and archives. Visit BHL at https://www.biodiversitylibrary.org. 